\title{
Analysis on the Teaching Model of Independent College under the Background of MOOC
}

\author{
Qinggong Ma \\ Changzhou University Huaide College, China 214500
}

Keywords: MOOC; Independent college; Teaching mode; Teaching conditions

\begin{abstract}
As a new type educational method, MOOC plays a distinctly important role in promoting the educational development and greatly impacts the traditional classroom teaching. It breaks the limitations of time, language and region and provides the curriculum resources from first-class schools and teachers, promoting the rapid development of education. Under the background of MOOC, the multimedia technology can make the knowledge and the abstract contents more specific and contribute to stronger flexibility, interestingness and practicality of the classroom. Big differences in the teaching model and the training objectives exist between independent colleges and ordinary universities. Independent colleges need to renovate the talent training program in accordance with social needs for talents and MOOC resources, in order to improve students' comprehensive qualities and employment competitiveness. This paper analyzes the characteristics of MOOC and the feasibility for independent colleges to carry out the MOOC teaching model and proposes countermeasures to solve problems in the teaching of independent colleges, so as to lay a solid foundation for the cultivation of high-quality talents according to the requirements of social development.
\end{abstract}

\section{Introduction}

The MOOC is the shortened form of the Massive Open Online Course, having been accepted and popularized worldwide and become a new teaching model and the trend of development. The soaring development of science and technology as well as information has supported the MOOC, using the MOOC resources to store resources rapidly and effectively spreading the MOOC resources. The rapid development of MOOC greatly challenges the traditional teaching model, methods, contents and the management system. The internet information technology promotes the popularization of excellent courses and Netease Open Course and the ceaseless development of online education, but people's attitudes toward MOOC are different. Teachers should know the important responsibilities, grasp the origin, characteristics and structure of MOOC according to the development of MOOC and innovate in the teaching model, to train high-quality talents meeting the requirements of social development.

\section{Analysis on the Characteristics of MOOC}

Wide Audiences. Because the MOOC is open and large-scale and carried out on the network, the registration of MOOC platform is not restricted strictly. All the people can register on the MOOC platform to learn. Besides, most of the MOOC are free, so more learners choose the MOOC platform. Different from the traditional classroom teaching, MOOC doesn't limit the number of people and some courses have been selected by millions of people. People from different countries can register and learn if they are interested in the MOOC.

Strong Self-Regulation of MOOC Learning. In the MOOC platforms, the same platform will release courses of different disciplines, providing more choices for learners. The same course may have different versions of MOOC courses. Learners can compare according to their demands so that the effectiveness of course learning will be improved. Learners can learn the MOOC through online registration free from the limitations of time, knowledge background and learning place. However, it cannot effectively supervise and control the learners' learning. Students have to learn independently. It is very difficult for them to complete the whole learning process if they lack the independence ability and self-control ability. 
The Teaching Methods Are More Flexible. Most MOOC resources are directly stored in the web server for learners to learn at any time. It breaks the limitations in time and space of the traditional teaching, provides more flexible teaching methods and enables teachers to grasp the actual learning process of learners more flexibly. Most of the teachers' videos of MOOC are controlled between five minutes and ten minutes, conforming to students' learning rules and cognitive features, promoting students to effectively pay attention to the classroom learning and contributing to more ideal effects in reviewing the knowledge after class.

\section{Analysis on the Feasibility for Independent Colleges to Carry Out the MOOC Teaching Model}

Teaching Staff and Teaching Conditions. At present, according to the analysis on domestic resources, most MOOC platforms are maintained and operated by domestic high level universities. Most courses in the MOOC platform are taught and released by famous teachers in university and designed by professional teams with high cost. Universities have advantages in teaching staff, teaching conditions and funding. It is imperative to reform the traditional higher education. Independent colleges need to build the MOOC teaching model according to the characteristics of era development. Young teachers in independent colleges should receive attentions because it is easier for them to accept new things, so that the independent colleges have advantages of teaching staff in the teaching reform of MOOC. Although the independent colleges cannot be comparable to the public universities, it has basic teaching conditions to guarantee students' online learning. Therefore, the teaching staff and teaching conditions of independent colleges have promoted the implementation of MOOC teaching model.

Students' Integrated Quality. Compared with students in public universities, students in independent colleges have poorer ability in learning the theory, but they have more active thinking and strong practical ability. Independent colleges expect to acquire abundant teaching resources as well as try new type learning patterns. The popularization of mobile terminal technology has provided technical supports for the online learning of independent colleges and has laid a solid foundation for them to implement the MOOC teaching model. It is a great challenge for independent colleges, especially the problems in MOOC platform. Because the MOOC requires fragmented knowledge, it has very high demands for teachers to control the knowledge. Meanwhile, problems exist in the construction cost of MOOC teaching model and students' assessment. Independent colleges should seize the advantages of MOOC according to the physical truth and build the new type MOOC teaching model, effectively combine the traditional classroom with the MOOC and exploit the advantages of them to the full, so as to improve the teaching quality.

\section{Problems in the Teaching of Independent Colleges}

Depend too much on universities. The development of times has provided effective development ways for independent colleges to innovate in the MOOC teaching model and adjust the MOOC teaching layout. Independent colleges can optimize the allocation of educational resources and realize the effective teaching. They still depend on universities because of the short history and the lack of school-running experience. For example, independent colleges lack clear objective of talents training and depend on universities in the provision of specialty and curriculum, paying more attention to the research-oriented talents, impossible to meet the requirements of local economic development and market development. Independent colleges should train applied talents according to the characteristics of social and economic development and then effectively differentiate from the universities and pay more attention to the practical teaching. Ideal teaching effectives cannot be achieved because the same syllabus is used without considering students' individual difference.

Lack High Level Teaching Staff. At present, most independent colleges employ university teachers to teach according to the teaching objectives of universities. The curriculum provision attaches more importance to the research-oriented teaching and the teaching of theoretical knowledge, failing to meet the objective of training applied talents. Most teachers in independent colleges are young. There are a small number of full-time teachers. Young teachers enter the independent colleges to teach after 
graduating from universities without sufficient teaching and management experience. Although part-time teachers from universities have rich teaching experience and high academic level, it is very difficult to adjust the objectives of talents training effectively. Therefore, the independent colleges lack independence because the educational resources and teacher resources of universities cannot meet the objective of talents training of independent colleges.

\section{Analysis on the Teaching Model of Independent Colleges under the Background of MOOC}

Apply the MOOC Teaching Model to the Liberal Optional Course and the Common Required Course of Independent Colleges. Independent colleges need to integrate the resources and environment advantage of universities and continuously improve students' employment competitiveness and overall quality according to the requirements of society for talents in the actual development. Therefore, in the teaching of MOOC, it is necessary to exert the leading role of scientific educational idea, renovate the training mode of new type talents and improve students' integrated quality. Independent colleges should support the MOOC teaching on the policy level and make the course assessment more scientific. Most liberal optional courses are taught by full-time teachers in independent colleges. Compared with the specialized courses, it receives fewer attentions from teachers and students, resulting in non-ideal teaching effect. Although some independent colleges have gradually introduced online courses, they are not free. The liberal optional courses are provided once a week with straightaway contents and taught according to students' interests and hobbies, which more or less meet the requirements of MOOC teaching. Compared with the liberal optional course, most Massive Open Online Courses are free with less teaching cost. Independent colleges should cooperate with MOOC platforms, bring the contents of MOOC into the teaching of liberal optional courses and build a high quality teaching system, reducing the teaching costs and improving the teaching quality. Besides, with more choices, most of the common required courses insist on the unified teaching requirement and effectively carry out the MOOC teaching model.

Integrate the Teaching Model of Flipped Class in the Teaching of Independent Colleges. The traditional teaching of independent college consists of knowledge instruction and knowledge internalization. Teachers impart knowledge in class and students internalize the knowledge through after-class assignments and practice. The so-called flipped class means students preview before class and timely record problems in the independent study. In classroom teaching, teachers answer the questions raised by students and encourage them to discuss and internalize the knowledge. The flipped class effectively integrates the advantages of traditional education and online education and builds an efficient and scientific teaching form. At present, most full-time teachers of independent colleges are postgraduates with richer specialized knowledge but lack of teaching strategies and experience, so that it cannot improve the efficiency of classroom teaching. Most independent colleges focus on teaching in a traditional way. In the teaching of flipped class, independent colleges can encourage teachers to transform the traditional classroom teaching and let students watch the teaching videos and complete the tasks assigned by teachers before class and teach students face to face according to different learning statuses. Besides, independent colleges should realize the teaching of flipped class step by step to improve the effectiveness of MOOC teaching. Most teachers of independent colleges record the video by themselves, but because of the lack of teaching experience and the limitation of teaching fund, it is necessary to effectively combine the MOOC teaching model with the flipped classroom teaching, in order to promote the teaching reform of independent colleges.

Apply the MOOC Teaching Model to the Vocational and Technical Courses. Currently, the MOOC teaching model has been applied to the teaching of vocational and technical courses. Students can acquire the corresponding professional certificate after completing the course learning. Independent colleges pay more attention to training the applied talents required by the social development. Students can be encouraged to take related courses and provided with the opportunity to improve the vocational and employment ability. On the other hand, most teachers of independent colleges are postgraduates just graduating from universities, lacking practical and work experience, so it is impossible to carry out high level vocational and technical courses. The MOOC teaching model can make up for the unqualified 
teaching ability of teachers. It can also be used to research the teaching cases. The high quality courses and excellent teachers of famous universities can guide the teaching design. Meanwhile, it helps to enrich the teaching resources and improve teachers' ability in vocational education and their actual teaching level. In talents training, independent colleges should adhere to the teaching principle of teaching students in accordance with their aptitudes and build new type talent training mode to improve students' occupational qualities and comprehensive qualities and lay a solid foundation for the development of them according to the effectiveness of the MOOC teaching model and students' actual demands.

\section{Conclusion}

Different from the traditional classroom teaching, the MOOC teaching model can effectively use the multimedia technology, making the teaching and abstract contents concrete. In the actual development, independent colleges need to innovate in the MOOC teaching model in accordance with the development of the era and effectively promote the open teaching. Independent colleges need to provide the efficient and diversified teaching and improve the actual teaching quality because it doesn't have the brand advantage and the number of people taking the college entrance examination reduces. Besides, they should promote the information construction, apply the MOOC teaching model to teaching and promote teachers to grasp the scientific teaching methods, to continuously improve teachers' information accomplishment and the management effectiveness. The MOOC teaching model should be applied to the actual teaching, promoting students to seek more scientific development roads, recognize themselves more comprehensively and letting students develop better..

\section{Acknowledgement}

Project of Philosophy and Social Science Research in Colleges and Universities in Jiangsu Province (2016SJD880217);Changzhou University Huaide Colleage teaching research subject (2016HDJY08)

\section{References}

[1]siemens,G. Connectivism:A Learning Theory for the Digital Age[J].International Journal of Instructional Technology and Distance Learning,2(1):3-10.

[2]Barnes C. MOOCs: The Challenges for Academic Librarians [J]. Australian Academic \& Research Libraries, 2013 (ahead-of-print): 1-13.

[3]siemens, G..What is the Theory that Underpins Our MOOCs [EB/OL].[2013-12-02].http://www.elearnspace.org/blog/2012/06/03/what-is-the-theory-that-underpin s-our-Moocs/.

[4]Siemens G. Massive Open Online Courses: Innovation Education? [M]. Commonwealth of Learning, Athabasca University Press, 2013.

[5]Cormier,D..Success in a MOOC [EB/OL] .[2013-12-08]. http://www.youtube.com/watch?v=r8av YQ5Zq M0

[6]Siemens, G..How to Participate in an Open Online Course[EB/OL].[2013-12-05].

http://gsiemens.tumblr.com/post/10153633521/how-to-participate-in-an-open- online-course.

[7]Koutropoulos,A.\&Hogue,R.J.(2012).How to Succeed in a Massive Online Open

Course(MOOC) [EB/OL].[2013-11-20].

http://www.learningsolutionsmag.com/articles/1023/how-to-succeed-in-a-massive-

online-open-course-mooc.

[8]Martin F G. Will massive open online courses change how we teach? [J]. Communications of the ACM, 2012, 55(8): 26-28.

[9]Day J A,Foley J D. Evaluating a web lecture intervention in a human computer interaction course

[J]. Education, IEEE Transactions on, 2006, 49(4): 420-431. 
[10]De Waard,I.,Abajian,S.\&Sean,M.et al.Using m Learning and MOOCs to Understand Chaos, Emergence, and Complexity in Education[J].The International Review of Research in Open and Distance Learning, 12(7):94-115.

[11]Jenny Mackness,Marion Waite, George Roberts, Elizabeth Lovegrove. Learning in a Small, Task-Oriented Connectivist MOOC: Pedagogical Issues and Implications for Higher Education[J]The International Review of Research in Open and Distance Learning,2013,(10):141-155. 